\title{
Expression and Activities of Matrix Metalloproteinases under Oscillatory Shear in IL-1-Stimulated Synovial Cells
}

\author{
Hui Bin Sun, ${ }^{1,2}$ Razi Nalim, ${ }^{3}$ and Hiroki Yokota ${ }^{1,2,3}$ \\ ${ }^{1}$ Department of Biomedical Engineering, Indiana University-Purdue University Indianapolis, \\ Indianapolis, Indiana, USA \\ ${ }^{2}$ Department of Anatomy and Cell Biology, Indiana University-Purdue University Indianapolis, \\ Indianapolis, Indiana, USA \\ ${ }^{3}$ Department of Mechanical Engineering, Indiana University-Purdue University Indianapolis, \\ Indianapolis, Indiana, USA
}

\begin{abstract}
Matrix metalloproteinases (MMPs) are known to play a critical role in tissue disintegration, and an elevated level of MMPs is observed in synovium and synovial fluid of joints with rheumatoid arthritis. During joint movement, synovial tissue receives various mechanical stimuli, but effects of mechanical challenges on regulation of MMPs in rheumatic synovium are poorly understood. Focusing on cellular responses to oscillatory fluid shear in human synovial cells, we determined the expression of MMP-1 and MMP-13 by polymerase chain reaction and immunoblotting as well as proteolytic activities of total MMPs by a fibril degradation assay and zymography. The results revealed that $\sim 0.5 \mathrm{dyn} / \mathrm{cm}^{2}$ oscillatory shear at $1 \mathrm{~Hz}$ not only reduced an $\mathrm{mRNA}$ level and a protein level of MMP-1 and MMP-13, but it also decreased collagenase and gelatinase activities of total MMPs. Furthermore, the induction of the MMP expression and activities by interleukin-1 was suppressed by the oscillatory shear. Interestingly, the oscillatory shear upregulated the mRNA expression of TIMP-1 and TIMP-2. Our results support a potential role of oscillatory shear in regulating expression and activities of MMPs in the presence and the absence of proinflammatory cytokine.
\end{abstract}

Keywords Interleukin 1, MMP, Rheumatoid Arthritis, Shear Stress, Synovium.

\section{INTRODUCTION}

Rheumatoid arthritis (RA) is a chronic inflammatory joint disease causing stiffening and swelling of diarthrodial joints [1]. Although a direct cause of RA remains unclear, proliferation

Received 16 October 2001; revised 29 January 2002; accepted 31 January 2002.

Address correspondence to Hiroki Yokota, PhD, Department of Anatomy and Cell Biology, Indiana University School of Medicine, 635 Barnhill Drive, MS-504, Indianapolis, IN 46202, USA. E-mail: hyokota@iupui.edu and outgrowth of synovial tissue is an initial pathologic symptom and proinflammatory cytokines such as interleukin-1 (IL-1) and tumor necrosis factor alpha $(\mathrm{TNF}-\alpha)$ are known to induce inflammation of synovial lining [2, 3]. Synovial tissue of RA is sensitive to various stresses including heat, oxidative stress, and mechanical loading, and stress signaling molecules such as heat shock proteins and mitogen-activated protein kinases are found to be activated $[4,5]$. A regular use of diarthrodial joints induces fluid-driven cyclic shear stress [6], and therefore elucidating responses to oscillatory shear as well as an interaction of shear with cytokine induction will help understand a role of mechanical factors in degradation of joint tissue. Compared with effects of shear stress on chondrocytes such as a release of cytokines and an increase in synthesis of collagen and proteoglycans, little is known about shear responses of synovial tissue [7-10].

A family of zinc-binding proteolytic enzymes known as matrix metalloproteinses (MMPs) is considered to play a critical role in the destruction of articular cartilage [11]. MMPs were initially classified into collagenases, gelatinases, and stromelysins together with a membrane type on the basis of substrate specificity and cellular location. The family continues to grow with the most recent member identified as MMP-26 (endometase), although a number of MMPs such as MMP-7 (matrilysin) and MMP-12 (metalloelastase) do not readily fit into any of the above four classes [12]. MMPs such as MMP-1 (collagenase 1), MMP-2 (gelatinase A), MMP-3 (stromelysin 1), MMP-11 (stromelysin 3), and MMP-13 (collagenase 3) are upregulated in synovium and synovial fluids of patients with RA [13-16]. Interestingly, a protein level of tissue inhibitors of metalloproteinases (TIMPs), a family of natural MMP inhibitors, also is elevated in RA synovial fluids [16, 17]. We previously found an altered expression of MMPs under 0-10 dyn/ $\mathrm{cm}^{2}$ uniform shear in RA synovial cell cultures. Low shear at $<3 \mathrm{dyn} / \mathrm{cm}^{2}$ reduced the 
mRNA expression of MMP-1, MMP-3, and MMP-13 and high shear at $>5 \mathrm{dyn} / \mathrm{cm}^{2}$ increased their mRNA levels together with gelatinase activity of total MMPs [18]. Synovial cells in vivo experience a variety of mechanical stresses and strains, and oscillatory shear represents a stress component associated with joint rotation. However, to our knowledge, no study has been performed to investigate a biophysical role of oscillatory shear in MMP or TIMP regulation, and the effects of oscillatory shear on MMP activities in the presence of proinflammatory cytokines are not understood.

In this study we addressed a specific question as to whether gentle oscillatory shear stress at $<1 \mathrm{dyn} / \mathrm{cm}^{2}$ would suppress IL1 -induced expression and activities of MMPs. Cellular responses to mechanical stimuli may differ depending on cell types [1922]. We used two synovial cell cultures derived from patients with RA. One culture was an MH7A cell line previously used in examining cellular responses to uniform shear [23, 24], and the other culture was a primary cell culture at passage 6 . These synovial cells are particularly suited for our study since their MMP expression and activities are stimulated by inflammatory cytokines such as IL-1. An mRNA level of MMP-1 and MMP13 were determined in these cell cultures by semiquantitative polymerase chain reaction (PCR) as well as real-time PCR, and collagenase activity and gelatinase activity of total MMPs were assayed by fibril degradation spectrofluorometry and zymography. The results showed that the gentle oscillatory shear for $1 \mathrm{hr}$ not only reduced the mRNA and protein levels of MMP-1 and MMP-13, but also suppressed IL-1-induced MMP expressions and activities.

\section{MATERIALS AND METHODS}

\section{Cell Culturing}

To examine responses of RA synovial cells to fluid-driven oscillatory shear, we used two sources of cells such as a MH7A cell line (Riken Cell Bank, Japan) and RA00-02 primary cells. The use of human cell cultures was approved by the Indiana University-Purdue University Indianapolis Institutional Review Committee. The cell cultures were derived from patients with RA who underwent synovectomy, and normal control cells were not included in this study. MH7A was an established cell line derived from the knee joint of an RA patient [23], and RA00-02 primary cells were isolated from the knee joint of a patient with RA at Indiana University Medical Center. In brief, RA00-02 synovial tissue was minced and cells were dissociated as previously described [25]. Cells in the supernatant were pelleted and cultured in a T-25 flask in a RPMI1640 medium supplemented with $20 \%$ fetal calf serum and antibiotics. At passage one, $\sim 80 \%$ of cells were macrophage-like cells and $20 \%$ of cells were fibroblast-like cells. As passages continued, the proportion of fibroblast-like cells increased.

We used MH7A cells at passage $\sim 10$ and RA00-02 cells at passage 6 , where over $98 \%$ cells consisted of fibroblast-like synoviocytes. Cells were cultured in a $3.5-\mathrm{cm}$ petri plate coated with type I collagen (Becton Dickinson Labware) at a concentration

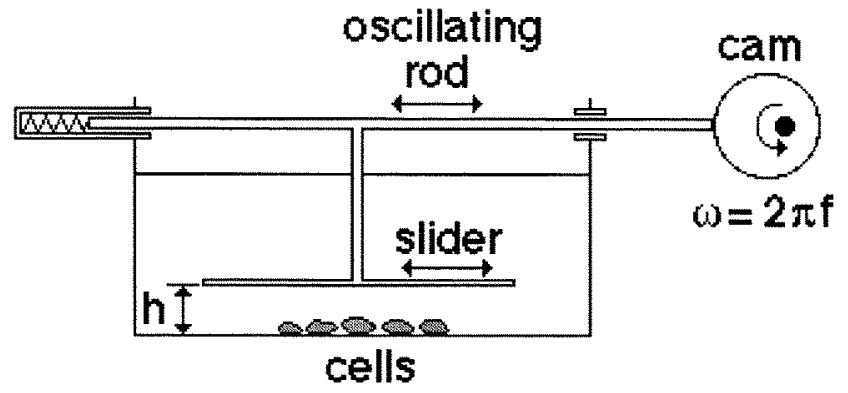

Figure 1. Schematic diagram of the mechanical loader used in the study. A slider was placed parallel to the culture surface and driven by a cam connected to an oscillating rod. The distance between the slider and the culture surface (h) was adjustable and set to $0.2 \mathrm{~cm}$.

of $2 \mu \mathrm{g} / \mathrm{cm}^{2}$, and they were exposed to shear at $\sim 80 \%$ confluency in a RPMI1640 medium supplemented with $0.5 \%$ fetal calf serum. In stimulating cells with IL-1, cells were first grown for 3-4 days in the media containing $10 \%$ fetal calf serum. A concentration of $5-10 \mathrm{ng} / \mathrm{ml}$ human IL-1 $\beta$ (CalBiochem) was effective in inducing MMPs when cells were preincubated in a media with a serum $0-0.5 \%$ for $1-2$ days. To minimize artifacts related to cellular starvation, we preincubated cells in the media with $0.5 \%$ fetal calf serum for $12 \mathrm{hr}$ and then used $50 \mathrm{ng} / \mathrm{ml}$ IL- $1 \beta$ for stimulation [26, 27].

\section{Oscillatory Shear Stress}

Fluid-driven oscillatory shear was given for $1 \mathrm{hr}$ by using a custom-made oscillatory flow device (Figure 1). A slider in the device was positioned horizontally parallel to a surface of a culture plate and it was oscillated by an electric motor along the culture surface in a sinusoidal motion at $1 \mathrm{~Hz}$.

Shear stress to cells was estimated by using a Couette-flow approximation in a pair of parallel plates as $\tau_{\max }=2 \pi \mu \mathrm{f} / \mathrm{h}$, where:

- $\tau_{\max }=$ maximum shear stress $\left(\mathrm{dyn} / \mathrm{cm}^{2}\right)$.

- $\mu=$ viscosity (poise).

- $\mathrm{f}=$ sinusoidal frequency $(\mathrm{Hz})$.

- $\mathrm{h}=$ distance between the slider and the culture plate (cm) [28].

In our experiment, $\tau_{\max }$ was calculated as $0.5 \mathrm{dyn} / \mathrm{cm}^{2}$ with $\mu=0.016$ poise, $\mathrm{f}=1 \mathrm{~Hz}$, and $\mathrm{h}=0.2 \mathrm{~cm}$. The shear condition in this study was selected to simulate subtle mechanical stimuli observed in a routine repetitive motion. In a uniform flow, MMP$1 \mathrm{mRNA}$ was downregulated under the shear at $2 \mathrm{dyn} / \mathrm{cm}^{2}$ (data not shown).

\section{Reverse Transcription (RT)-PCR}

Total RNA was isolated using RNeasy mini-kits (Qiagen, CA), and the isolated RNA was reverse-transcribed by MMLV reverse transcriptase. The cDNAs corresponding to MMP-1, MMP-13, TIMP-1, and TIMP-2 were amplified by semiquantitative PCR and by real-time PCR [29], and glyceraldehyde-3phosphate dehydrogenase (GAPDH) was used as control. The 
TABLE 1

Primers for semiquantitative PCR.

\begin{tabular}{|c|c|c|}
\hline Gene & Sense and antisense primers & cDNA size (bp) \\
\hline \multirow[t]{2}{*}{ MMP-1 } & 5'-CACAGCTTTCCTCCACTGCTGCTGC-3' & \multirow[t]{2}{*}{396} \\
\hline & 5'-GGCATGGTCCACATCTGCTCTTGGC-3' & \\
\hline \multirow[t]{2}{*}{ MMP-13 } & 5'-TGGTGGTGATGAAGATGATTTGTCT-3' & \multirow[t]{2}{*}{376} \\
\hline & 5'-AGTTACATCGGACCAAACTTTGAAG-3' & \\
\hline \multirow[t]{2}{*}{ TIMP-1 } & 5'-CCTGGCTTCTGGCATCCTGTT-3' & \multirow[t]{2}{*}{280} \\
\hline & 5'-GGGACCTGTGGAAGTATCCGC-3' & \\
\hline \multirow[t]{2}{*}{ TIMP-2 } & 5'-CAGTGAGAAGGAAGTGGACTC-3' & \multirow[t]{2}{*}{300} \\
\hline & 5'-CATCTGGTACCTGTGGTTCAG-3' & \\
\hline \multirow[t]{2}{*}{ GAPDH } & 5'-CCACCCATGGCAAATTCCATGGCA-3' & \multirow[t]{2}{*}{600} \\
\hline & 5'-TCTAGACGGCAGGTCAGGTCCACC-3' & \\
\hline
\end{tabular}

PCR primers and probes are listed in Tables 1 and 2 . In semiquantitative PCR, a reaction was hot-started at $94^{\circ} \mathrm{C}$ for $5 \mathrm{~min}$ including 28 cycles at $94^{\circ} \mathrm{C}$ for denaturation $(1 \mathrm{~min}), 55-65^{\circ} \mathrm{C}$ for annealing (1 min), and $72^{\circ} \mathrm{C}$ for extension (45 sec to $1 \mathrm{~min}$ $30 \mathrm{sec}$ ). Amplified DNA fragments by semiquantitative PCR were separated in agarose gel by electrophoresis. In real-time PCR, we used ABI Prism 7700 sequence detection system (PE Corporation). Amplified cDNAs were quantified by fluorescent intensity of fluorescent probes, and a threshold cycle, $\mathrm{C}_{\mathrm{T}}$, was determined to estimate difference in a starting cDNA copy number with and without oscillatory shear.

\section{Immunoblotting}

To detect any effect of oscillatory shear on a protein level of MMP-1 and MMP-13, we conducted an immunoblot assay using antibodies specific to the latent and active forms of MMP-1 or MMP-13 (mouse monoclonal $\mathrm{IgG}_{1}$, CalBiochem). An expected molecular size was $42 / 46 \mathrm{kDa}$ (MMP-1) and $48 \mathrm{kDa}$ (MMP-13) for an active enzyme without modification, and $57 \mathrm{kDa}$ (MMP-1) and $60 \mathrm{kDa}$ (MMP-13) for a latent form. Total proteins were collected from cells, and $\sim 10 \mu \mathrm{g}$ of protein extracts were separated by electrophoresis on $10 \%$ SDS PAGE gel. Proteins on gel were transferred electrophoretically onto nitrocellulose membranes (Hybond, Amersham), and the membranes were incubated in a PBS-T (pH7.5) buffer consisting of
$5 \%$ blocking reagent (Amersham) and $0.1 \%$ Tween 20. Individual membranes were incubated overnight in the PBS-T buffer containing antihuman antibodies against MMP-1 or MMP-13, and a protein level of MMPs was assayed with ECL detection reagents (ECL Western blotting analysis system, Amersham).

\section{MMP Activity Assays in Cell Culture Media}

To assay collagenase activity of total MMPs in response to oscillatory shear with and without IL-1 stimulation, we conducted a fibril degradation assay using an EnzChek gelatinase/ collagenase assay kit (Molecular Probes). Isolated protein extracts from the culture media were incubated at room temperature for $2 \mathrm{hr}$ with type I collagen as a substrate in a reaction buffer consisting of $500 \mathrm{mM}$ Tris- $\mathrm{HCl}$ (pH7.6), $1.5 \mathrm{M}$ $\mathrm{NaCl}, 50 \mathrm{mM} \mathrm{CaCl}$, and $2 \mathrm{mM}$ sodium azide. The collagen substrate was heavily labeled with green fluorophores, and digestion by collagenases isolated from the culture media would liberate fluorophores from a quenching effect of nearby fluorophores. Fluorescent intensity with an absorption maximum at $\sim 495 \mathrm{~nm}$ and an emission maximum at $\sim 515 \mathrm{~nm}$ was measured by FluoroMax-2 spectorfluorometer (Instruments S.A.).

To assay gelatinase activity of total MMPs in the culture media, we conducted zymography using gelatinase as a substrate [18]. MMP-1 and MMP-13, assayed by RT-PCR in this study, are known to possess gelatinase activity [11]. Briefly, the

TABLE 2

Primers and probes for real-time PCR.

\begin{tabular}{|c|c|c|c|}
\hline Gene & Sense and antisense primers & Probe & cDNA size (bp) \\
\hline MMP-1 & 5'-CTCAATTTCACTTCTGTTTTCTG-3' & 5'-FAM-CACAACTGCCAAATGGGC & 76 \\
\hline MMP-13 & 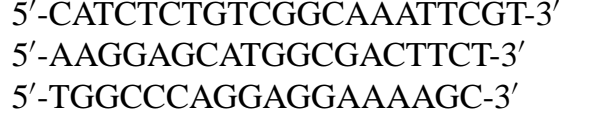 & $\begin{array}{l}\text { TTGAAGC-TAMRA-3' } \\
\text { 5'-FAM-CCCTCTGGCCTGCTGGCTCA-TAMRA-3' }\end{array}$ & 72 \\
\hline TIMP-1 & $\begin{array}{l}\text { 5'-TGCCGCATCGCCGAGAT-3' } \\
\text { 5'-ATGGTGGGTTCTCTGGTG-3' }^{\prime}\end{array}$ & 5'-FAM-CCAGCGCCCAGAGAGAC-TAMRA-3' & 51 \\
\hline TIMP-2 & $\begin{array}{l}\text { 5'-CACCAGGCCAAGTTCTTC-3' } \\
\text { 5'-CGGTACCACGCACAGGA-3' }\end{array}$ & 5'-FAM-CCTGCATCAAGAGAAGTGAC-TAMRA-3' & 60 \\
\hline
\end{tabular}


culture media were concentrated by 10 -fold using a centrifugal concentrator (Nanosep, Pall Filtron Corp.), and $50 \mu \mathrm{l}$ of the concentrate was mixed with $100 \mu \mathrm{l}$ of the sample buffer containing $500 \mathrm{mM}$ Tris- $\mathrm{HCl}$ (pH6.8), 25\% glycerol, $10 \%$ SDS, and $1 \%$ Bromophenol blue. Then, $20 \mu \mathrm{l}$ of the protein mixture was loaded on a zymographic gel and separated by electrophoresis. After electrophoresis, the gel was incubated in a renaturation buffer (Bio-Rad) at room temperature for $30 \mathrm{~min}$ and then in a development buffer (Bio-Rad) at $37^{\circ} \mathrm{C}$ overnight. The gel was rinsed and stained with $0.5 \%$ Coomassie blue in $40 \%$ methanol and $10 \%$ acetic acid. After de-staining and rinsing, gelatinase activity was detected as a light translucent band over a blue background.

\section{Data Analysis}

Immunoblots for MMP-1 and MMP-13 and zymographic gels were imaged by a flatbed scanner (VistaScan 3.0, Umax), and band intensity was quantified using Adobe PhotoShop software (version 4.0, Adobe Systems). RT-PCR experiments, zymography, and fibril degradation spectrofluorometry were performed twice for each of the two cell lines, and immunoblotting was conducted twice using MH7A cells. To test statistical significance of expression and activities of MMPs and TIMPs, we conducted a $t$-test using StatView software (version 5.0, SAS
Institute). The $p$ value less than .01 was considered statistically significant.

\section{RESULTS}

\section{Alteration in mRNA Levels}

The oscillatory shear, employed in this study, had an amplitude of $\sim 0.5 \mathrm{dyn} / \mathrm{cm}^{2}$ with a frequency of $1 \mathrm{~Hz}$. Using MH7A and RA00-02 synovial cells, we first investigated an mRNA level of MMP-1, MMP-13, TIMP-1, and TIMP-2 under 1-hr oscillatory shear. Semiquantitative PCR revealed that the oscillatory shear reduced a level of MMP-1 mRNA and MMP-13 mRNA, but it elevated a level of TIMP-1 mRNA and TIMP-2 mRNA (Figure 2A). The observed shear response was evident in MH7A cell line as well as RA00-02 primary cells.

\section{Suppression of IL1-Induced MMP-1 mRNA and MMP-13 mRNA}

Using semiquantitative PCR, we next examined effects of the oscillatory shear on the mRNA expression of MMPs and TIMPs in the presence of IL-1 stimulation. The 1-hr incubation with $50 \mathrm{ng} / \mathrm{ml}$ IL-1 elevated the mRNA expression of MMP-1, MMP-13, TIMP-1, and TIMP-2 in two synovial cell cultures (Figure 2A). A simultaneous application of the oscillatory shear
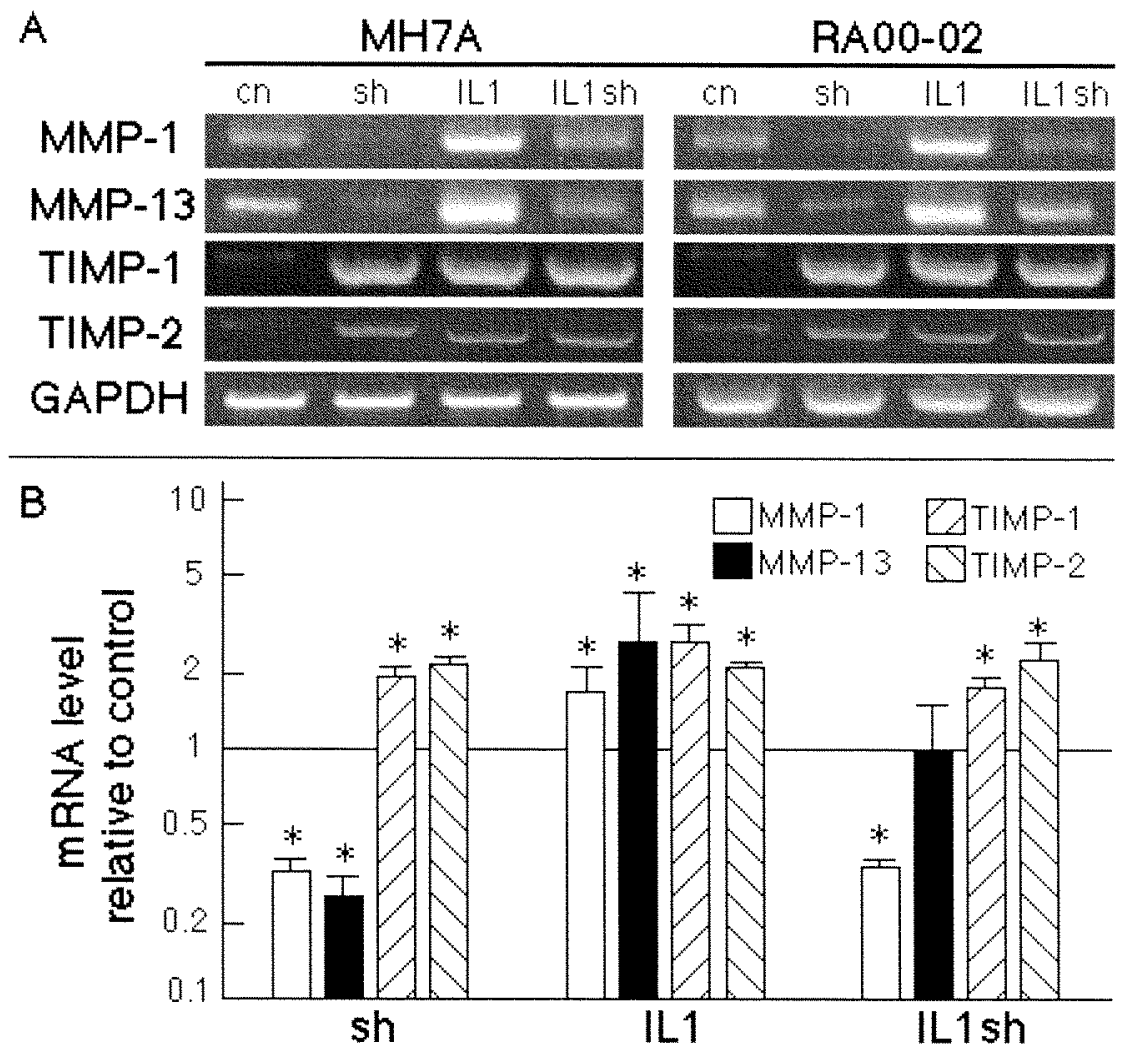

Figure 2. Altered mRNA expression of MMP-1, MMP-13, TIMP-1, and TIMP-3. (A) Semiquantitative PCR where $\mathrm{cn}=\mathrm{control}$ without any treatment; sh = shear; IL1 = interleukin-1 stimulation; and IL1sh = IL-1 stimulation and shear. (B) Quantification of mRNA alteration by real-time PCR. The asterisk indicates statistically significant alteration $(p<.01)$ compared with control without any treatment. 
suppressed the IL-1-elevated mRNA level of MMP-1 and MMP13, but it maintained the increased level of TIMP-1 mRNA and TIMP-2 mRNA (Figure 2A). Suppression by the oscillatory shear was consistent in a duplicated set of experiments for MH7A cells and RA00-02 primary cells.

To quantify the observed alteration in mRNA levels by the oscillatory shear, we used real-time PCR and determined a threshold cycle that indicated a required number of PCR cycles to synthesize a prescribed amount of cDNA products. A difference in a threshold cycle with and without shear was used to estimate alteration in mRNA levels by the oscillatory shear (Figure 2B). The results from real-time PCR confirmed the reduction in MMP-1 mRNA and MMP-13 mRNA as well as the increase in TIMP$1 \mathrm{mRNA}$ and TIMP-2 mRNA that we observed previously in semiquantitative gel images (Figure 2A). Compared with a control level, the average mRNA under the oscillatory shear was $32 \%$ (MMP- $1, p<.01$ ) and 26\% (MMP-13, $p<.01$ ). The oscillatory shear suppressed the IL-1-induced mRNA level from $170 \%$ down to $34 \%$ (MMP-1) and from $270 \%$ down to $100 \%$ (MMP-13) of the control level. Regardless of the IL-1 stimulation, the TIMP mRNA level was higher than the control level by 1.8-2.7 times (TIMP-1) and 2.2-2.3 times (TIMP-2). To summarize, the mRNA level of MMP-1 and MMP-13 was decreased by the oscillatory shear in the presence and the absence of IL-1 induction, whereas the level of TIMP-1 mRNA and TIMP-2 mRNA was increased by the oscillatory shear and IL-1 stimulation.

\section{Reduction in Protein Level of MMP-1 and MMP-13}

The immunoblot assay using antibodies specific to either MMP-1 or MMP-13 exhibited a consistent alteration at a protein level to the alteration observed at the mRNA level. In either MMP-1 or MMP-13 blotting, a single band near a molecular mass of $60-70 \mathrm{kDa}$ was detected. Its intensity was substantially reduced under the 1-hr gentle oscillatory shear, while the IL-1 stimulation increased the protein level (Figure 3). Like the mRNA suppression by shear, the elevated protein level by IL-1 was suppressed by the simultaneous shear treatment (Figure 3). An estimate of molecular size in the blots, $\sim 10 \mathrm{kDa}$ heavier than the unmodified active form, suggested that antibodies detected either active enzymes with modifications or latent MMP proenzymes with uncleaved precursor peptides $[30,31]$.

\section{Reduction in Collagenase Activity and Gelatinase Activity}

Having known that the gentle oscillatory shear at $1 \mathrm{~Hz}$ reduced the mRNA level as well as the protein levels of MMP-1 and MMP-13, we examined gelatinase activities and collagenase activities of total MMPs under shear. MMP-1 (collagenase 1) and MMP-13 (collagenase 3) are known to possess gelatinase activity as well as collagenase activity, and therefore any alteration in their activities can be detected in an assay using collagen and gelatin as substrates. Note that our activity assays were sensitive not only to MMP-1 and MMP-13, but also to any other MMPs responsive to oscillatory shear. In the fibril degradation assay, collagenase activity was reduced under the oscillatory shear, and
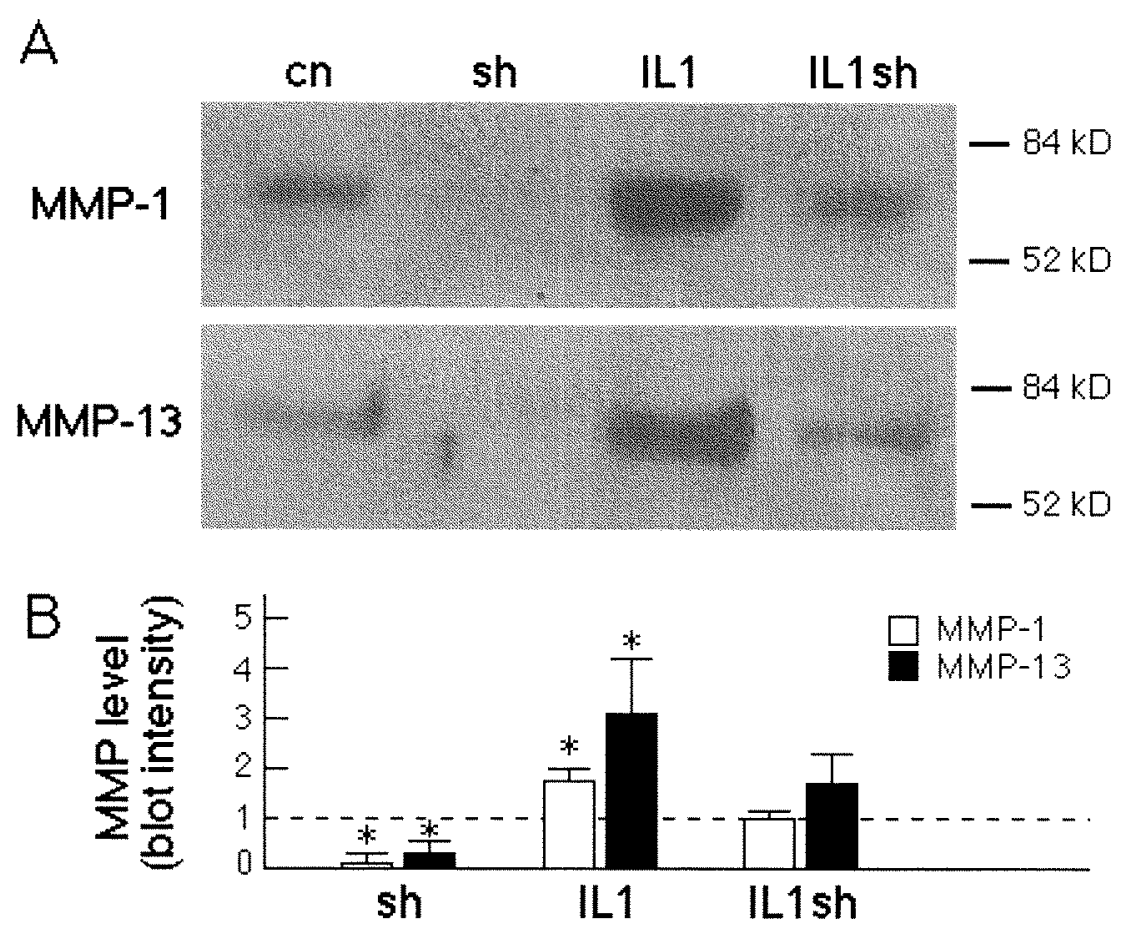

Figure 3. Altered protein levels of MMP-1 and MMP-13 in MH7A synovial cells by IL-1 stimulation and/or gentle oscillatory shear. (A) Two immunoblots using antibodies specific to either MMP-1 or MMP-13 show a single band corresponding to molecular mass in the range of 60-70 kDa. The lanes are $\mathrm{cn}=\mathrm{control}$ without any treatment; $\mathrm{sh}=$ shear; IL1 = interleukin-1 stimulation; and IL1sh = IL-1 stimulation and shear. (B) Protein levels of MMP-1 and MMP-13 normalized by a control level without any treatment. The bar represents a standard deviation, and the asterisk indicates statistically significant alteration with $p<.01$. 


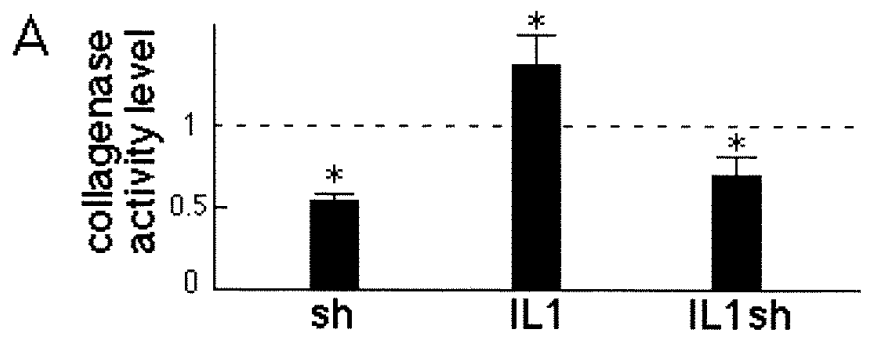

B
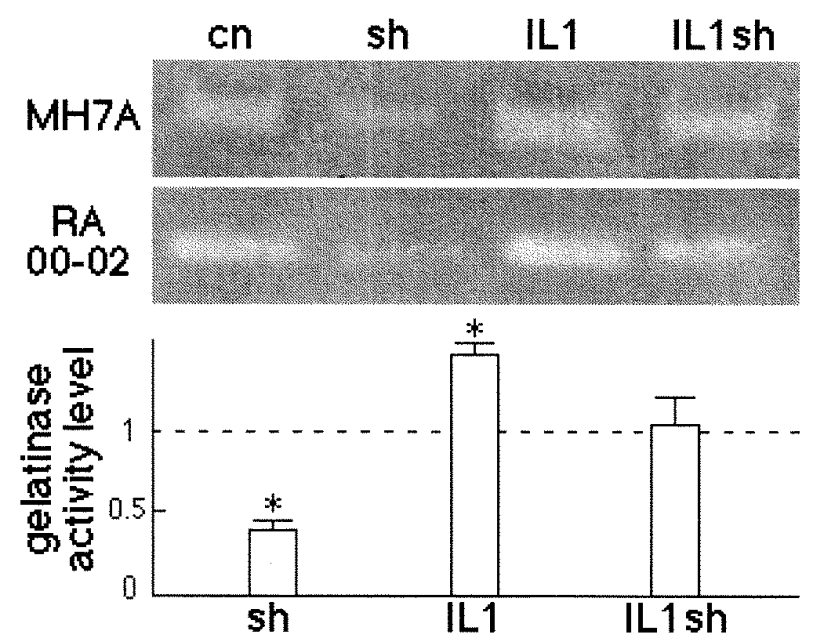

Figure 4. Alteration in collagenase activity and gelatinase activity by the oscillatory shear for $1 \mathrm{hr}$. The asterisk indicates statistically significant difference $(p<.01)$ compared with control without any treatment. The symbols are $\mathrm{cn}=$ control without any treatment; $\mathrm{sh}=$ shear; IL1 = interleukin-1 stimulation; and IL1sh = IL-1 stimulation and shear. (A) Levels of collagenase activity normalized by a control level. The bar represents a standard deviation. (B) Zymographic gel and levels of gelatinase activity normalized by a control level. The bar represents a standard deviation.

compared with the control level the observed activity level was $\sim 54 \%(p<.01)$ (Figure 4A). The stimulation by IL-1 increased the activity up to $136 \%(p<.01)$, and the IL-1-elevated activity was reduced down to $70 \%$ by the oscillatory shear $(p<.01)$ (Figure 4A).

In zymographic gels showing a single bright band at $\sim 65 \mathrm{kDa}$, we observed that gelatinase activity was downregulated under the $1-\mathrm{Hz}$ gentle oscillatory shear by $\sim 60 \%(p<.01)$ and that the oscillatory shear suppressed the IL-1-induced increase in gelatinase activity by $29 \%(p<.01)$ (Figure 4B). A faint band at $\sim 45 \mathrm{kDa}$ also was detected in the gels. The observed alteration in gelatinase activity was consistent in the duplicated experiment for each of the two cell cultures.

\section{DISCUSSION}

Synovial tissue in vivo is exposed to a high degree of mechanical stimuli including strain, normal stress, and shear. It is sensitive to various environmental stresses and known to present the earliest symptom of rheumatic inflammation. In this study using MH7A cell line and RA00-02 primary cells, we examined cellular responses to oscillatory shear and their linkage to inflammatory responses by IL-1 induction. Four independent measurements on mRNA levels, protein levels, gelatinase activity, and collagenase activities consistently supported the downregulation of MMPs under oscillatory shear at $\sim 0.5 \mathrm{dyn} / \mathrm{cm}^{2}$ for $1 \mathrm{hr}$. Furthermore, the oscillatory shear suppressed the expression of MMP-1 and MMP-13 as well as activities of total MMPs induced by IL-1. Contrary to the expression and activities of MMPs, the mRNA levels of TIMP-1 and TIMP-2 were upregulated by the oscillatory shear. The results suggest that the oscillatory fluid shear can play an inhibitory role in regulation of MMPs at a transcriptional level as well as at a posttranscriptional level.

Although the measured alteration in the mRNA level and the protein level were specific to MMP-1 and MMP-13, reduction in gelatinase and collagenase activities were attributable to total MMPs. Recent analyses of MMP mRNA and protein levels in synovial fluid and plasma of patients with RA showed elevated levels of many MMPs including MMP-1, MMP-2 (gelatinase A), MMP-3, and MMP-8 (collagenase 3) [13, 16]. Therefore, the observed reduction in collagenase activity and gelatinase activity by the oscillatory shear may, at least in part, result from downregulation of other MMPs. Our semiquantitative RT-PCR data showed no decrease in MMP-2 mRNA and a slight decrease in MMP-8 mRNA under the oscillatory shear (data not shown), and we postulate that the expression and activities of individual MMPs as well as TIMPs can be regulated coordinately but not identically in response to shear. Many MMPs including MMP-1 and MMP-13 consist of multiple AP-1 and Ets binding sites in their promoter, and the mRNA expression of Jun and Ets- 1 are induced in RA synovial cells by mechanical stimuli [32]. A recent study of cellular responses to oscillating fluid shear using a rat osteoblast-like cell line has revealed inactivation of NF- $\kappa$ B that plays a role as a primary regulator of stress responses [33]. A differential combination of regulatory DNA elements including AP-1 site, PEA-3 site (Ets binding site), and NF- $\kappa$ B binding site seems to contribute to varying shear responses of MMPs [34,35].

We used fibroblast-like synovial cells derived from patients with RA and observed downregulation of MMPs under the oscillatory shear for $1 \mathrm{hr}$. Synovial tissue consists of heterogeneous cell types including endothelial cells, macrophage-like cells, and fibroblast-like cells. In human chondrocyte cell cultures, we recently observed a downregulation of MMP mRNAs under a steady shear flow at $2-5 \mathrm{dyn} / \mathrm{cm}^{2}$ and upregulation at $10-20 \mathrm{dyn} / \mathrm{cm}^{2}$ (manuscript in preparation). Our current working hypothesis is that fluid-driven shear below a certain threshold value reduces expression and activities of MMPs in joint tissues and a threshold stress is cell-type dependent.

A dynamic nature of loading and compliance of articular cartilage allow synovial joints to be lubricated with a fluid film, and synovial fluid in a synovial cavity is mobilized by a sliding motion of articular surfaces or a pressure gradient within a joint [36]. Two widely used principles for simulating in vivo fluid shear are based on a Couette flow and a Poiseuille flow that induce shear by sliding a pair of plates and by generating a pressure gradient, respectively [37]. In this study, a Couette 
flow in a pair of parallel plates was used to generate oscillatory shear [38]. Fluid-driven shear in vivo during a joint motion contains varying oscillatory frequencies, and cellular responses may depend on oscillatory frequency as well as shear intensity and duration.

Mechanotransduction underlying the suppression of IL-1induced MMP activation is yet to be investigated. Cytokines such as TNF- $\alpha$ and IL- 1 have been identified as major pathogenic mediators in RA, and together with their receptors they are overexpressed in the synovial tissue and articular chondrocytes of patients with RA [4, 39, 40]. Several lines of evidence suggest a role of mitogen-activated protein kinases (MAPK) signaling pathways including the extracellular signal-regulated protein kinase (ERK), c-Jun amino-terminal kinase (JNK), and p38 pathways in the suppression of IL-1 induction. Proinflammatory cytokines have been demonstrated to induce ERK, JNK, and p38 signaling pathways [41-43], and JNK is required for MMP expression and joint destruction in inflammatory sinovium [44]. Individual MMPs under oscillatory shear can be regulated coordinately with variations by a combination of different signaling pathways (manuscript in preparation).

\section{SUMMARY}

The present study demonstrates for the first time that the specific oscillatory fluid flow has an inhibitory role in the expression of MMP-1 and MMP-13 and activities of total MMPs in synovial cells derived from patients with RA. Continuous passive motion was reported to improve postoperative and postinjury pediatric-orthopedic patients with progressive decrease in joint pain [45]. Because high shear stress is shown to activate proteolytic activities, it is premature to extend the results to possible physical therapies for RA patients [46, 47]. Further elucidation of cellular responses to shear in synovium and other joint tissue from patients with RA or osteoarthritis will contribute to evaluating effects of mechanical loading for stimulating or preventing progressive damage and subsequent loss of joint function.

\section{ACKNOWLEDGMENTS}

We appreciate Jim McAteer and Drew Rietjens for their support to cell cultures, and Paresh Sanghani and Irene Sun for technical assistance in spectrofluorometry. This study was supported in part by IUPUI Grant-In-Aid.

\section{REFERENCES}

[1] Arnett, F.C. (2000). Rheumatoid arthritis. In Textbook of Medicine, L. Goldman and Bennett J.C. (eds.), pp. 1492-1499 (W.B. Saunders, Philadelphia).

[2] Muller-Ladner, U. (1996). Molecular and cellular interactions in rheumatoid synovium. Curr. Opin. Rheumatol. 8:210-220.

[3] Muller-Ladner, U., Gay, R., and Gay, S. (1999). Signaling and effector pathways. Curr. Opin. Rheumatol. 11:194-201.

[4] Schett, G., Tohidast-Akrad, M., Steiner, G., and Smolen, J. (2001). The stressed synovium. Arthritis Res. 3:80-86.

[5] Konttinen, Y.T., Li, T.F., Hukkanen, M., Ma, J., Xu, J.W., and Virtanen, I. (2000). Fibroblast biology—signals targeting the synovial fibroblast in arthritis. Arthritis Res. 2:348-355.
[6] Dowson, D., and Jin, Z.M. (1986). Micro-elastohydrodynamic lubrication of synovial joints. Eng. Med. 15:63-65.

[7] Flannery, C.R., Little, C.B., Caterson, B., and Hughes, C.E. (1999). Effects of culture conditions and exposure to catabolic stimulators (IL-1 and retinoic acid) on the expression of matrix metalloproteinases (MMPs) and disintegrin metalloproteinases (ADAMs) by articular cartilage chondrocytes. Matrix Biol. 18:225-237.

[8] Smith, R.L., Trindade, M.C.D., Ikenoue, T., Mohtai, M., Das, P., Carter, D.R., Goodman, S.B., and Schurman, D.J. (2000). Effects of shear stress on articular chondrocyte metabolism. Biorheol. 37:95-107.

[9] Fujisawa, T., Hattori, T., Takahashi, K., Kuboki, T., Yamashita, A., and Takigawa, M. (1999). Cyclic mechanical stress induces extracellular matrix degradation in cultured chondrocytes via gene expression of matrix metalloproteinases and interleukin-1. J. Biochem. 125:966-975.

[10] Mow, V.C., Wang, C.C., and Hung, C.T. (1999). The extracellular matrix, interstitial fluid and ions as a mechanical signal transducer in articular cartilage. Osteoarthritis and Cartilage 7:41-58.

[11] Shingleton, W.D., Hodes, D.J., Bzrick, P., and Cawston, T.E. (1996). Collagenase: A key enzyme in collagen turnover. Biochem. Cell Biol. 74:759775 .

[12] Whittaker, M., and Ayscough, A. (2000). Matrix metalloproteinases and their inhibitors-current status and future challenges. Celltransmissions 17:3-14.

[13] Keyszer, G., Lambiri, I., Nagel, R., Keysser, C., Keysser, M., GromnicaIhle, E., Franz, J., Burmester, G.R., and Jung, K. (1999). Circulating levels of matrix metalloproteinases MMP-3 and MMP-1, tissue inhibitor of metalloproteinases 1 (TIMP-1), and MMP-1/TIMP-1 complex in rheumatic disease. Correlation with clinical activity of rheumatoid arthritis versus other surrogate markers. J. Rheumatol. 26:251-258.

[14] Konttinen, Y.T., Ainola, M., Valleala, H., Ma, J., Ida, H., Mandelin, J., Kinne, R.W., Santavirta, S., Sorsa, T., Lopez-Otin, C., and Takagi, M. (1999). Analysis of 16 different matrix metalloproteinases (MMP-1 to MMP-20) in the synovial membrane: Different profiles in trauma and rheumatoid arthritis. Ann. Rheum. Dis. 58:691-697.

[15] Wernicke, D., Seyfert, C., Hinzmann, B., and Gromnica-Ihle, E. (1996). Cloning of collagenase 3 from the synovial membrane and its expression in rheumatoid arthritis and osteoarthritis. J. Rheumatol. 23:590-595.

[16] Yoshihara, Y., Nakamura, H., Obata, K., Yamada, H., Hayakawa, T., Fujikawa, K., and Okada, Y. (2000). Matrix metalloproteinases and tissue inhibitors of metalloproteinases in synovial fluids from patients with rheumatoid arthritis or osteoarthritis. Ann. Rheum. Dis. 59:455-461.

[17] Henriet, P., Blavier, L., and Declerck, Y.A. (1999). Tissue inhibitors of metalloproteinases (TIMP) in invasion and proliferation. APMIS 107:111119.

[18] Sun, H.B., and Yokota, H. (2001). Messenger-RNA expression of matrix metalloproteinases, tissue inhibitors of metalloproteinases, and transcription factors in rheumatic synovial cells under mechanical stimuli. Bone 28:303-309.

[19] De Keulenaer, G.W., Chappell, D.C., Ishizaka, N., Nerem, R.M., Alexander, R.W., and Griendling, K.K. (1998). Oscillatory and steady laminar shear stress differentially affect human endothelial redox state: Role of a superoxide-producing NADH oxidase. Circ. Res. 82:1094-1101.

[20] Jacobs, C.R., Yellowley, C.E., Davis, B.R., Zhou, Z., Cimbala, J.M., and Donahue, H.J. (1998). Differential effect of steady versus oscillating flow on bone cells. J. Biomech. 31:969-976.

[21] Yang, J.H., Briggs, W.H., Libby, P., and Lee, R.T. (1998). Small mechanical strains selectively suppress matrix metalloproteinase-1 expression in human vascular smooth muscle cells. J. Biol. Chem. 273:6550-6555.

[22] Xu, Z., Buckley, M.J., Evans, C.H., and Agarwal, S. (2000). Cyclic tensile strain acts as an antagonist of IL-1b actions in chondrocytes. J. Immunol. 165:453-460.

[23] Miyazawa, K., Mori, A., and Okudaira, H. (1998). Establishment and characterization of a novel human rheumatoid fibroblast-like synoviocyte line, MH7A, immortalized with SV40T antigen. J. Biochem. 124:11531162. 
[24] Sun, H.B., and Yokota, H. (2001). Altered mRNA level of matrix metalloproteinase 13 in MH7A synovial cells under mechanical loading and unloading. Bone 28:399-403.

[25] Moe, S.M., Singh, G.K., and Bailey, A.M. (2000). $\beta-2$ microglobulin induces MMP-1 but not TIMP-1 expression in human synovial fibroblasts. Kidney Int. 57:2023-2034.

[26] Kolibas, L.M., and Goldberg, R.L. (1989). Effect of cytokines and antiarthritic drugs on glycosaminoglycan synthesis by bovine articular chondrocytes. Agents and Actions 27:245-249.

[27] Koch, A.E., Kunkel, S.L., Harlow, L.A., Mazarakis, D.D., Haines, G.K., Burdick, M.D., Pope, R.M., Walz, A., and Strieter, R.M. (1994). Epithelial neutrophil activating peptide-78: A novel chemotactic cytokine for neutrophils in arthritis. J. Clin. Inv. 94:1012-1018.

[28] Papanastasiou, T.C., Georgiou, G.C., and Alexandrou, A.N. (2000). Viscous Fluid Flow, pp. 195-196 (CRC Press, New York).

[29] Orlando, C., Pinzani, P., and Pazzagli, M. (1998). Developments in quantitative PCR. Clin. Chem. Lab. Med. 36:255-269.

[30] Stricklin, G.P., Eisen, A.Z., Bauer, E.A., and Jeffrey, J.J. (1978). Human skin fibroblast collagenase: Chemical properties of precursor and active forms. Biochem. 17:2331-2337.

[31] Ito, A., and Nagase, H. (1988). Evidence that human rheumatoid synovial matrix metalloproteinase 3 is an endogenous activator of procollagenase. Arch. Biochem. Biophys. 267:211-216.

[32] Borden, P., and Heller, R.A. (1997). Transcriptional control of matrix metalloproteinases and the tissue inhibitors of matrix metalloproteinases. Crit. Rev. Eukaryotic Gene Exp. 7:159-178.

[33] Kurokouchi, K., Jacobs, C.R., and Donahue, H.J. (2001). Oscillating fluid flow inhibits TNF- $\alpha$-induced NF- $\kappa$ B activation via an I $\kappa$ B kinase pathway in osteoblast-like UMR106 cells. J. Biol. Chem. 276:13499-13504.

[34] Qian, L., Liu, Y., Sun, H.B., and Yokota, H. (2002). Systems analysis of matrix metalloproteinases mRNA expression in skeletal tissues. Frontiers in Biosci. 7:126-134.

[35] Sun, H.B., Malacinski, G.M., and Yokota, H. (2002). Promoter competition assay for analyzing gene regulation in joint tissue engineering. Frontiers in Biosci. 7:169-174.
[36] Unsworth, A. (1991). Tribology of human and artificial joints. Proc. Instn. Mech. Engrs. 205:163-172.

[37] Brown, T.D. (2000). Techniques for mechanical stimulation of cells in vitro: A review. J. Biomech. 33:3-14.

[38] Nalim, R., Pekkan, K., Sun, H.B., and Yokota, H. Oscillating shear flow experiment and flow predictions (submitted).

[39] Abbot, S.E., Whish, W.J.D., Jennison, C., Blake, D.R., and Stevens, C.R. (1999). Tumour necrosis factor $\alpha$ stimulated rheumatoid synovial microvascular endothelial cells exhibit increased shear rate dependent leucocyte adhesion in vitro. Ann. Rhem. Dis. 58:573-581.

[40] Lefebvre, V., Peeters-Joris, C., and Vaes, G. (1990). Modulation by interleukin 1 and tumor necrosis factor $\alpha$ of production of collagenase, tissue inhibitor of metalloproteinases and collagen types in differentiated and dedifferentiated articular chondrocytes. Biochim. Biophys. Acto 1052:366-378.

[41] Chen, K.D., Li, Y.S., Kim, M., Li, S., Yuan, S., Chien, S., and Shyy, J.Y.J. (1999). Mechanotransduction in response to shear stress. J. Biol. Chem. 274:18393-18400.

[42] Chiquet, M. (1999). Regulation of extracellular matrix gene expression by mechanical stress. Matrix Biol. 18:417-426.

[43] Tseng, H., Peterson, T.E., and Berk, B.C. (1995). Fluid shear stress stimulates mitogen-activated protein kinase in endothelial cells. Circ. Res. 77:869-878.

[44] Han, Z., Boyle, D.L., Chang, L., Bennett, B., Karin, M., Yang, L., Manning, A.M., and Firestein, G.S. (2001). C-Jun N-terminal kinase is required for metalloproteinase expression and joint destruction in inflammatory arthritis. J. Clinical Inv. 108:73-81.

[45] Guidera, K.J., Hontas, R., and Ogden, J.A. (1990). Use of continuous passive motion in pediatric orthopedics. J. Ped. Ortho. 10:120-123.

[46] Stenstrom, C.H., Arge, B., and Sundbom, A. (1997). Home exercise and compliance in inflammatory rheumatic diseases-a prospective clinical trial. J. Rheumatol. 24:470-476.

[47] Dhondt, W., Willeys, T., Verbruggen, L.A., Oostendorp, R.A.B., and Duquet, W. (1999). Pain threshold in patients with rheumatoid arthritis and effect of manual oscillations. Scand. J. Rheumatol. 28:88-93. 
Copyright $\odot 2003$ EBSCO Publishing 
Copyright of Connective Tissue Research is the property of Taylor \& Francis Ltd and its content may not be copied or emailed to multiple sites or posted to a listserv without the copyright holder's express written permission. However, users may print, download, or email articles for individual use. 